\title{
L'affaire des Cacouacs, trois pamphlets contre les Philosophes des Lumières, présentation et notes de Gerhardt Stenger
}

Paola Sosso

\section{(2) OpenEdition}

\section{Journals}

Edizione digitale

URL: http://journals.openedition.org/studifrancesi/34713

DOI: $10.4000 /$ studifrancesi.34713

ISSN: 2421-5856

Editore

Rosenberg \& Sellier

\section{Edizione cartacea}

Data di pubblicazione: 1 novembre 2005

Paginazione: 418-419

ISSN: 0039-2944

\section{Notizia bibliografica digitale}

Paola Sosso, "L'affaire des Cacouacs, trois pamphlets contre les Philosophes des Lumières, présentation et notes de Gerhardt Stenger», Studi Francesi [Online], 146 (XLIX | II) | 2005, online dal 30 novembre 2015, consultato il 18 avril 2021. URL: http://journals.openedition.org/studifrancesi/34713 ; DOI: https://doi.org/10.4000/studifrancesi.34713

Questo documento è stato generato automaticamente il 18 avril 2021.

\section{cc)}

Studi Francesi è distribuita con Licenza Creative Commons Attribuzione - Non commerciale - Non opere derivate 4.0 Internazionale. 


\title{
L'affaire des Cacouacs, trois pamphlets contre les Philosophes des Lumières, présentation et notes de Gerhardt Stenger
}

\author{
Paola Sosso
}

\section{NOTIZIA}

L'affaire des Cacouacs, trois pamphlets contre les Philosophes des Lumières, présentation et notes de Gerhardt STENGER, Saint-Etienne, Publications de l'Université de Saint-Etienne, 2004, pp. 159.

1 La pubblicazione dei primi tomi dell'Encyclopédie provoca forti reazioni, come è noto, tra gli intellettuali e gli uomini politici. L'Avis utile, opera anonima del 1757, in cui i philosophes vengono per la prima volta definiti Cacouacs (col significato di méchants, partendo dall'etimologia greca) è il primo pamphlet raccolto in questo volumetto, che ha il pregio di ricostruire le vicende di una parte degli oppositori alla nuova filosofia proponendo alla riflessione alcuni testi poco noti. Nell'Avis utile i filosofi vengono presentati, con un ironico renversement del mito del buon selvaggio, come una popolazione barbara caratterizzata da una malvagità iperbolica: da qui la necessità di saperli identificare, suggerisce l'anonimo autore, per sapersi difendere da loro. A pochi mesi di distanza, sempre nel 1757, esce il Nouveau mémoire pour servir à l'histoire des Cacouacs di Jacob-Nicolas Moreau (1717-1803), avvocato, giornalista, storiografo, difensore dell'autorità del re. Il testo non intende attaccare nessun filosofo in particolare, come precisa l'autore nell'Avertissement, e si basa sull'idea che, in nome della natura, i Cacouacs giungono all'anarchia. Sulla scia di queste idee, che ebbero fortuna unicamente presso i contemporanei di Moreau, l'Abbé de Saint-Cyr (1699-1761) sous-précepteur del Delfino e membro dell'Académie Française, compone il Catéchisme et décisions des cas de conscience à l'usage des cacouacs (1759), in cui vengono elencati i 
precetti della nuova filosofia, pericolosi per il re e per la patria: si tratta, secondo l'autore, di una serie di mostruosità che non hanno bisogno di grandi commenti. Degni di rilievo anche le Annexes che completano questo volumetto: innanzitutto il Nouveau mémoire: L'Aléthophile ou ami de la vérité (1758) di La Harpe, in cui i nemici dei philosophes vengono presentati come dei mentitori che travisano i fatti e si contraddicono tra loro. Interessanti anche gli altri testi: un estratto delle Variétés morales et philosophiqes (1785) di Moreau, utile a meglio comprendere il pensiero dell'autore; un brano della recensione a opera di Fréron dell'Avis utile; il discorso pronunciato dall'abbé Batteux al suo ingresso all'Académie Française, nel quale viene fornito un significativo portrait di Saint-Cyr, e, in ultimo, un Petit supplément à l'histoire des cacouacs depuis la fin du XVIII ${ }^{e}$ siècle jusqu'au temps présent contenuto in una riedizione del Mémoire di Moreau del 1828. L'ortografia e la punteggiatura dei testi presentati sono state modernizzate; vengono fornite essenziali note a piè di pagina e una rapida bibliografia al termine dell'Introduzione. 